\title{
A GESTÃO TERRITORIAL DA EDUCAÇÃO NO BRASIL: INDEFINIÇÕES E TENSÕES INTERFEDERATIVAS ENTRE O PÚBLICO E O PRIVADO
}

\author{
Maura da Silva Miranda ${ }^{1}$ \\ Maria Couto Cunha ${ }^{2}$
}

\begin{abstract}
Resumo:
O artigo apresenta a síntese de uma pesquisa documental e bibliográfica de um projeto de tese de Doutorado em Educação na Universidade Federal da Bahia (UFBA) que discute a gestão da educação, as lacunas conceituais e operacionais do regime de colaboração e da cooperação federativa frente à proposta de consolidação do Sistema Nacional de Educação por meio da institucionalização de Consórcios Públicos (CP) e Arranjos de Desenvolvimento da Educação (ADE) em parceria público privado, no espaço territorial. O estudo busca investigar sob que ordenamentos jurídicos, concepções e interesses políticos tais arranjos se fundamentam e como eles vêm sendo disseminados no país. As análises sinalizam a urgência do debate sobre essas novas relações interfederativas, dadas às limitações que apresentam para assegurar o direito educacional no complexo federalismo brasileiro.
\end{abstract}

Palavras-Chaves: Estado brasileiro, educação, gestão territorial.

\section{Resumen}

El artículo presenta la síntesis de una investigación documental y bibliográfica de um proyecto de tesis Doctorado en educación en Universidad Federal de Bahia (UFBA) que discute la gestión de la educación, las brechas conceptuales y operacionales del régimen de colaboración y el Cooperación Federativa ante la propuesta de consolidar el sistema educativo nacional através de la institucionalización de los consorcios públicos (CP) y de los acuerdos de desarrollo de la educación (ADE), en una asociación público privada, em el ámbito territorial. El estudio busca investigar bajo qué ordenanzas legales, concepciones e intereses políticos se basanen tales arreglos y cómo se handiseminado en el país. Los análisis señalan la urgencia del debate sobre estas nuevas relaciones interfederacións, dadas a las limitaciones que presentan para assegurar el derecho educativo en el complejo federalismo brasileño.

Palabras clave: estado brasileño, educación, ordenación territorial.

\footnotetext{
${ }^{1}$ Doutoranda da Linha de Gestão e Políticas da Educação da Universidade Federal da Bahia (UFBA). Mestre em Educação (UFBA). Licenciada em Letras Vernáculas (UNEB). Professora de Educação Básica da Rede Estadual de Ensino da Bahia. E-mail:mauravalente@yahoo.com.br

${ }^{2}$ Doutora em Educação pela Universidade Federal da Bahia (UFBA). Mestre em Educação (UFBA). Graduação em Ciências Sociais (UFBA). Professora do Programa de Pós-Graduação em Educação da Faculdade de Educação da Universidade Federal da Bahia. e-mail mariacoutocunha@gmail.com
} 


\section{INTRODUÇÃO}

O presente trabalho emana da necessidade de conhecer como vêm sendo desenvolvidos os processos de institucionalização das relações interfederativas para assegurar a cooperação e a colaboração federativas na gestão da educação no Brasil através dos Consórcios Públicos (CP) face ao novo cenário estabelecido pela Lei n 11.107/2005 (BRASIL, 2005) e através de parcerias público privado por meio dos Arranjos de Desenvolvimento da Educação (ADE), regulamentadas pelo Conselho Nacional de Educação, Resolução nº 1, de 23 de janeiro 2012.

É sabido que, devido às fortes desigualdades regionais, a Constituição Federal de 1988 - CF estabeleceu o Pacto Federativo, a ser efetivado através da cooperação federativa e do regime de colaboração, para assegurar o equilíbrio do desenvolvimento no país e a equidade na garantia de direitos, entre eles o direito a uma educação com garantia de padrões mínimos de qualidade. Todavia, como essas relações interfederativas não foram devidamente regulamentadas no federalismo brasileiro, ao longo dos anos assiste-se a edições de diversos formatos de relações intergovernamentais para a assistência técnica e financeira da União por meio de fundos, convênios, contratos em caráter temporário, limitando a gestão sistêmica e o financiamento da educação no país e mitigando o direito a uma educação de qualidade em todos os estados e municípios brasileiros.

Nesse contexto de indefinições, assiste-se nos últimos anos a uma mobilização nacional para a criação de um Sistema Nacional de Educação, para que sejam devidamente institucionalizadas a cooperação e a colaboração federativas e, no centro desse debate o Consórcio Público (CP) e o Arranjo de Desenvolvimento da Educação (ADE) são apresentados como novas estratégias de gestão cooperativas e colaborativa, sendo amplamente disseminadas pelo Ministério da Educação. Muitas parcerias vêm sendo firmadas no Brasil em formatos de CP e ADE, este último contando com a participação de institutos e fundações diversas, sejam estas de caráter empresarial ou de interesse público, com vista a promover a gestão de políticas educacionais no espaço territorial.

O estudo buscou investigar como vem sendo regulamentados e disseminados tais arranjos educacionais no país, propostos como estratégias para a institucionalização do Sistema Nacional da Educação (SNE). Através da análise dos ordenamentos jurídicos e os argumentos políticos e teóricos existentes em torno da questão, buscou-se perceber sobre que concepção de Estado esses modelos de gestão estão embasado, quais seus interesses e possibilidades de contribuir com a melhoria da gestão educacional. 


\section{A GESTÃO DA EDUCAÇÃO NO FEDERALISMO BRASILEIRO}

A gestão da educação no federalismo brasileiro tem sido, desde sempre, estudada, debatida e analisada no cenário nacional, tanto no campo acadêmico quanto no campo político. Uma das principais razões dos recorrentes debates em torno da questão é a lacuna legislativa em torno do Pacto Federativo, bem como a existência de contradições entre o discurso jurídico e o percurso político para sua operacionalização no federalismo cooperativo implantado no Brasil.

As Constituições de 1891, 1937, 1946, 1967 e 1988 afirmaram a forma republicana do Estado brasileiro, organizando-o de forma federada. O federalismo implica, dentre muitos outros princípios, na descentralização política, administrativa e financeira, conferindo autonomia aos entes federados. Mas, dada as fortes desigualdades regionais, muitos dos entes subnacionais não possuem autonomia financeira, o que limita sua capacidade administrativa na gestão das políticas públicas. O pressuposto básico do federalismo cooperativo implantado no Brasil é o estímulo à integração nas relações intergovernamentais entre as unidades subnacionais e o governo central na gestão das políticas, com ênfase na equalização de condições de vida em todo o território nacional (ARAÚJO, 2013).

Conhecedores das limitações da maioria dos municípios brasileiros no que se refere ao financiamento e gestão das políticas educacionais, sobretudo aqueles situados em regiões menos desenvolvidas, os legisladores conformaram no texto da CF de 1988 que as desigualdades regionais no Brasil seriam equalizadas por meio das formas de cooperação e do regime de colaboração - mencionados nos artigos $23^{3}$ e $211^{4}$ da referida constituição, respectivamente, sendo que a cooperação deveria ser regulamentada em legislação complementar e o regime de colaboração se efetivaria na relação sistêmica entre os sistemas de ensino. Por meio desse Pacto Federativo a União assumiu a responsabilidade de prestar assistência técnica e financeira aos entes federados que apresentam limitações no que se refere às condições de assegurar suas obrigações em termos de oferta de ensino. Porém, passadas três décadas pós a CF de 1988, a regulamentação do referido Pacto Federativo, a ser efetivado pela normatização em legislação complementar das formas de cooperação e pela instituição de um arranjo institucional entre os entes federados capaz de viabilizar a operacionalização

\footnotetext{
${ }^{3}$ BRASIL, Constituição Federal. art. 23, Parágrafo único. Leis complementares fixarão normas para a cooperação entre a União e os Estados, o Distrito Federal e os Municípios, tendo em vista o equilíbrio do desenvolvimento e do bem-estar em âmbito nacional. (Redação dada pela Emenda Constitucional no. 53 de 2006).

${ }^{4}$ BRASIL, Constituição Federal. art. 211- A União, os Estados, o Distrito Federal e os Municípios organizarão em regime de colaboração seus sistemas de ensino.
} 
do regime de colaboração em matéria educacional, ainda não foi definido de forma a viabilizar um Sistema Nacional de Educação para articulação entre os entes.

Neste cenário de indefinições, a União vem protelando a definição da cooperação federativa por meio de uma política permanente de financiamento da educação pública, negligenciando a garantia do direito à educação com equidade no país. Embora algumas políticas do Ministério da Educação nos últimos anos tenham promovido significativos avanços, os problemas estruturais da gestão federativa permanecem. Entre as principais políticas implementadas, merece destaque a Emenda Constitucional $n^{\circ} 53$ que criou o Fundo de Manutenção e Desenvolvimento da Educação Básica e de Valorização dos Profissionais de Educação (FUNDEB). Esta política de fundo de financiamento temporário, embora não apresente condições de solucionar os problemas das desigualdades regionais, representou notável avanço na cooperação federativa da educação, possibilitando a redistribuição dos recursos diretamente para o ente federado onde o aluno encontra-se matriculado, ampliando a participação da União no financiamento da Educação Básica.

Além do FUNDEB, a institucionalização do Plano de Desenvolvimento da Educação (PDE) em 2007 e do Plano de Ações Articuladas (PAR) pelo conforme Decreto nº 6.094 de 2007, possibilitaram o acesso a políticas de assistência técnica e financeira por parte dos entes subnacionais, fato que têm promovido melhorias significativas na educação pública. Porém, também estas políticas não resolvem o problema nevrálgico do federalismo brasileiro, pois não assegura o financiamento equitativo e permanente para a gestão da educação e a devida relação sistêmica entre os entes. Assim, a federação brasileira continua com o grande desafio, desde a promulgação da Constituição Federal de 1988, de equalizar as oportunidades educacionais e assegurar um padrão mínimo nacional de qualidade.

Em 2014, com a aprovação do Plano Nacional de Educação, mediante a Lei 13.005/2014, foi assegurado na Meta 20, Estratégia 9, que no prazo de 2 (dois) anos o país regulamentaria em lei complementar, o parágrafo único do art. 23 da Constituição federal de forma a estabelecer as normas para a cooperação entre a União, os Estados, o Distrito Federal e os Municípios em matéria educacional para garantir o equilíbrio na repartição das responsabilidades e o efetivo cumprimento das funções redistributiva e supletiva da União no combate às desigualdades educacionais regionais, com especial atenção às regiões Norte e Nordeste, bem como articularia o Sistema Nacional de Educação, em atenção ao o art. 211 da mesma constituição (PNE 13.005/2014). Mas, até o momento, a meta não foi efetivada. 
Segundo Cury (2012), a regulamentação para a cooperação federativa no Brasil, tratase de matéria da mais alta importância e significado para o conjunto das ações públicas e, em especial, para a manutenção e desenvolvimento do ensino. A ausência de sua normatização tem dificultado o entendimento para a materialização de um modelo de financiamento equitativo e permanente, gerando lacunas e conflitos interpretativos entre os termos 'cooperação' e 'colaboração'. Em face desses conflitos interpretativos, o regime de colaboração foi prerrogativa legal para a realização de apoios financeiros temporários por meio da adesão voluntária de políticas públicas via convênios e contratos temporários, protelando assim a definição, por lei complementar, das formas cooperativas necessárias.

Sobre essa discussão, Abicail (2014) afirma que do ponto de vista semântico, pode-se ponderar que os termos ‘colaboração' e ‘cooperação' possuem a mesma significação, mas, do ponto de vista constitucional, há que distinguir seus sentidos. Enquanto a cooperação implica diretamente em financiamento, o regime de colaboração é o ordenamento jurídico por meio do qual a União exerce seu papel de regulação da política educacional entre os sistemas de ensino. Para o desenvolvimento das ações reguladoras entre os entes federados, existem ações privativas da União, concorrentes e comuns, todas estabelecidas na Constituição Federal. Cada ente é autônomo entre si, com competências e atribuições prioritárias, mas precisa agir de forma sistêmica. Essa distribuição de competências e atribuições de cada ente federado, regidas sobre os princípios da autonomia, em regime de colaboração, com a coordenação da União, possibilita unidade e diversidade sem antinomias, ou seja, ausência de incompatibilidades normativas (CURY, 2010).

A ausência de normas claras para o regime de colaboração, fez com que vários Estados da federação o regulamentassem em diferentes formatos, entre os sistemas de ensino de seus respectivos municípios. Entre as experiências mais estruturadas estão às desenvolvidas pelos Estados do Acre, do Ceará, de Mato Grosso e de Rio Grande do Sul, conforme pesquisas realizadas por Abrucio e Segatto (2016). A Bahia, a partir de 2007 iniciou um trabalho na Secretaria de Educação do Estado por meio do Programa de Apoio os Municípios (PROAM), com a finalidade de fortalecer o regime de colaboração entre o Estado e os municípios baianos, por meio de assistência técnica aos gestores e equipes municipais, mas esta iniciativa ainda carece de regulamentações no Estado. Vê-se que a ausência de um Sistema Nacional de Educação fez com que cada Estado buscasse regulamentar formas colaborativas distintas entre seus municípios, reproduzindo uma fragmentação nas relações sistêmica no país. Por isso, é urgente a criação de um Sistema Nacional de Educação, de forma a institucionalizar a gestão articulada da educação entre os entes. Sua criação tem sido defendida desde os Pioneiros da 
Educação na década de 30, ganhou força nas Conferências Nacionais de Educação (CONAE) 2010/2014, mas, a questão continua sem definição.

Em 2011 foi criada no Ministério da Educação, a Secretaria de Articulação dos Sistemas de Ensino (SASE), cuja principal meta percorrida foi o aprofundamento de estudos para a formulação de uma proposição de regulamentação do SNE, suficientemente colaborativo e cooperativo, capaz de garantir a gestão e o financiamento equitativo de das políticas, reduzindo as desigualdades educacionais. Essa tarefa exigiu da SASE esforços e diálogos constantes junto às instituições representativas da educação nacional, como União dos Dirigentes Nacionais de Educação (UNDIME), União Nacional dos Conselhos Municipais de Educação (UNCME), Conselho Nacional de Dirigentes Estaduais de Educação (CONSED), Conselho Nacional de Educação, dentre outros. No bojo das discussões e estudos realizados consolidou-se o entendimento de que, para haver uma gestão sistêmica das políticas de Estado, precisava-se ser fomentada a constituição e a promoção de arranjos institucionais capazes de garantir a articulação entre os entes federados que viessem a servir de modelos para a instituição do SNE (RIBEIRO, 2011). Desse debate surgem as propostas de arranjos para o regime de colaboração horizontal no espaço territorial, mediante a atuação dos Consórcios Públicos e das parcerias em ADE’s numa relação público privado.

\section{PROPOSTAS PARA O REGIME DE COLABORAÇÃO NO ESPAÇO TERRITORIAL}

Como proposta para se efetivar o regime de colaboração, a SASE e CNE, passaram a propor a instituição de arranjos educacionais nos espaços territoriais, por meio de novas relações interfederativas horizontais de associativismo municipal, como estratégia para a operacionalização do regime de colaboração. Por meio do Parecer CNE/CEB Nº: 9/2011, homologado pelo Ministro de Educação Fernando Haddad, publicado no D.O.U de 22/11/2011, Seção 1, Pág. 23, o CNE aprovou a regulamentação de arranjos educacionais propondo 02 (dois) principais modelos: os Consórcios Públicos e os Arranjos de Desenvolvimento da Educação, em parceria público privado.

Segundo o Parecer CNE $n^{\circ}$ 09/2011, os arranjos educacionais podem contribuir diretamente para reduzir as descontinuidades das políticas públicas na área de educação, superar as dificuldades da ausência de equipes técnicas especializadas nos municípios, possibilitar a elaboração de planos e projetos de financiamento da educação e acelerar o 
desenvolvimento educacional. Os ADE's são compreendidos como mais uma forma de colocar em prática o regime de colaboração e podem congregar a participação do Estado, da União, de instituições privadas e não governamentais, que "assumem o objetivo comum de contribuir para o desenvolvimento da educação em determinado território, sem que haja para isso a necessidade de transferência de recursos públicos para tais instituições" (PARECER CNE/CEB Nº. 09/2011).

Considerando o pronunciamento do CNE via Parecer CNE/CEB No: 9/2011 e os estudos publicados pela SASE sobre a proposta dos arranjos foram elaborados os PL N. ${ }^{\circ}$ 5.519/2013 e o PL 413/2014, que propõem a regulamentação do Sistema Nacional de Educação (SNE), sendo o Consórcio Público e o ADE em parceria público privado, estratégias de gestão em rede da educação no Estado.

O Consórcio Público Intermunicipal (CPI), apresentado como uma das formas de associativismo apenas entre entes federados tem como objetivo promover o desenvolvimento territorial por meio de uma gestão compartilhada da educação municipal, visando à eficiência da gestão dos serviços públicos. Nas últimas décadas tem sido crescente o número de $\mathrm{CP}$ firmados entre municípios no Brasil, decorrentes das novas regulamentações deste formato de gestão na administração indireta do Estado. Mas, apesar dessa ampliação no número de consórcio ser um fenômeno recente na administração pública, os CP não são novidades no Estado brasileiro. Desde a primeira Constituição Federal em 1891 eles já existiam, embora se constituíssem apenas como contratos entre municípios ou estados (PRATES, 2010).

Com a CF de 1937 os consórcios passaram à condição de associação de municípios, como pessoa jurídica de direito público. A CF de 1946 ampliou a visão desse formato de gestão como estratégia de cooperação federativa regional, culminando na criação do Banco de Desenvolvimento Regional do Extremo Sul (BRDE) em 1961, que se constituiu enquanto primeira autarquia de consórcio público no Brasil. Com o golpe militar em 1964, a gestão do Estado foi centralizada em um modelo de Estado Unitário e nesse período, com a CF de 1967, os $\mathrm{CP}$ foram desestruturados, passando a ter um caráter meramente administrativo, sem personalidade jurídica (RIBEIRO, 2006).

Com a redemocratização brasileira na década de 80 e a aprovação da CF de 1988, os municípios constituíram-se em entes federados, sendo-lhes transferidas competências político-administrativas de serviços públicos em diversas áreas, tornando imperativa a busca por captação de recursos para o desenvolvimento local. O texto constitucional abriu possibilidades de diversos formatos de consórcios, convênios, associação, contratos de 
serviços. Em 1998, a Emenda Constitucional no 195 , de 4 de junho de 1998 alterou o art. 241 da CF indicando a necessidade da normatização precisa dos formatos de CPIs. Por meio do disposto no art. 26 da referida EC n ${ }^{\circ}$ 19/98, tornou-se possível a edição de uma lei específica para a gestão consorciada no país, a Lei no 11.107, de 6 de abril de 2005.

Segundo estudos de Prates (2004), no universo de 5.564 municípios brasileiros, 4.537 declararam que participavam de alguma modalidade de Consórcio Público Municipal, somando um percentual de $81,5 \%$ do total de municípios brasileiros e esse número só aumenta, depois da aprovação da Lei no 11.107, regulamentada pelo Decreto no 6.017, de 17 de janeiro de 2007. Conforme o referido decreto, Consórcio Público é pessoa jurídica formada exclusivamente por entes da Federação e integra à Administração Indireta, constituído como associação pública, com personalidade jurídica de direito público e natureza autárquica, ou como pessoa jurídica de direito privado sem fins econômicos, capaz de estabelecer relações de cooperação federativa (BRASIL, Decreto 6.017/07).

As recentes legislações ampliaram consideravelmente os objetivos dos CP e suas áreas de atuação, a saber: gestão associada de serviços públicos; prestação de serviços, assistência técnica, execução de obras e fornecimentos de bens; compartilhamento de instrumentos, equipamentos, pessoal, licitação e admissão de pessoal; produção de informações e estudos técnicos; intercâmbio de experiências entre os consorciados; administração dos serviços e recursos consorciados; assistência técnica, extensão, treinamento, pesquisa e ações de políticas de desenvolvimento socioeconômico local e regional, incluindo aí a gestão das políticas educacionais. Essa ampliação das possibilidades de atuação dos consórcios fez com que os municípios se articulassem na busca de parcerias por meio deste formato.

A partir desse novo ordenamento, o consórcio apresenta-se como um importante modelo de articulação territorial no Brasil, tornando-se um instrumento de gestão compartilhada, por meio do qual os municípios podem realizar ações conjuntas que, sozinhos, certamente encontrariam maiores dificuldades e limitações. Muitos municípios, visando fortalecer o diálogo institucional e promover a articulação cooperativa, têm se organizado em CP para definição de agendas comuns e captação de recursos para a gestão das políticas públicas.

Em 2010, o Ministério do Planejamento Orçamento e Gestão inicia um trabalho de orientação para a formação de consórcios no país, afirmando que a gestão consorciada, além

\footnotetext{
${ }^{5}$ Art. 24- O artigo 241 da Constituição Federal passa a vigorar com a seguinte redação: Art. 241 - A União, os Estados, o Distrito Federal e os Municípios disciplinarão por meio de lei os consórcios públicos e os convênios de cooperação entre os entes federados, autorizando a gestão associada de serviços públicos, bem como a transferência total ou parcial de encargos, serviços, pessoal e bens essenciais à continuidade dos serviços transferidos.
} 
de possibilitar o compartilhamento do poder, pode produzir capital social local com a participação de associações civis, sindicatos, imprensa e lideranças políticas na gestão das políticas, constituindo uma rede colaborativa de relações institucionais capazes de combater a fragmentação e a descontinuidade das políticas públicas em contextos locais.

Estudos de César (2008) e Prates (2010) confirmam alguns benefícios da gestão consorciada, que vão desde a racionalização do uso dos recursos até o fortalecimento dos vínculos com a formação ou consolidação de uma identidade regional e/ou territorial, capaz de favorecer o desenvolvimento econômico local, intermunicipal, potencializando as condições de negociação dos municípios e fortalecendo a autonomia municipal. Porém, na área educacional os Consórcios Públicos são em menor número no Brasil, conforme demonstra tabela seguinte:

Tabela 3: Número de Municípios, total e com existência de consórcio intermunicipal segundo as Grandes Regiões do Brasil, em algumas áreas, em 2011

\begin{tabular}{|c|c|c|c|c|}
\hline \multicolumn{5}{|c|}{ Número de Municípios } \\
\hline \multirow{2}{*}{$\begin{array}{l}\text { Grandes } \\
\text { Regiões }\end{array}$} & \multicolumn{4}{|c|}{$\begin{array}{c}\text { Com existência de Consórcio Público intermunicipal na área da } \\
\text { administracão }\end{array}$} \\
\hline & Total & Educação & Saúde & Desen. Social \\
\hline Brasil & 5.565 & 280 & 2.288 & 232 \\
\hline Norte & 449 & 12 & 25 & 8 \\
\hline Nordeste & 1.794 & 86 & 312 & 66 \\
\hline Sudeste & 1668 & 95 & 974 & 75 \\
\hline Sul & 1.188 & 73 & 865 & 59 \\
\hline Centro Oeste & 466 & 14 & 112 & 24 \\
\hline
\end{tabular}

Fonte: IBGE, Diretoria de Pesquisas, Coordenação de população e Indicadores Sociais, Pesquisa de Informações Básicas Municipais, 2011.

Na Bahia, dentre os consórcios existentes nos 27 Territórios de Identidade da Bahia, 08 (oito) preveem em seus Estatutos e Planos de Execução Orçamentária o desenvolvimento de políticas na área educacional, conforme dados publicados na homepage institucional dos CP's e no Diário Oficial Eletrônico dos Municípios (DOEM). Dentre esses, somente 04 se destacam na articulação e mobilização de políticas educacionais: o Consórcio de Desenvolvimento Sustentável do Vale do Jiquiriçá (CDSVJ), o Consórcio Intermunicipal da Mata Atlântica (CIMA), o Consórcio Intermunicipal da APA do Pratigi (CIAPRA) e o Consórcio Intermunicipal de Desenvolvimento do Circuito do Diamante da Chapada Diamantina (CIDCD). De maneira geral, as ações desenvolvidas pelos CP's na Bahia na área educacional têm sido bastante limitadas e carecem de estudos para mapear e analisar suas reais contribuições para a gestão da educação nos Territórios de Identidade. 
A pouca atuação dos CP na área educacional no Brasil, frente às inúmeras demandas de formação, orientação e assessoramento técnico na área educacional de muitos municípios, exigem dos municípios a busca de parcerias para desenvolver projetos inovadores de educação. Assim, outros sujeitos têm despertado o interesse em firmar parcerias colaborativas com esses entes federados em outros formatos de gestão, de parceria público privado. Agentes da iniciativa privada nacionais, regionais e internacionais, como fundações e institutos, com o discurso de promoção da governança local vêm se articulando e propondo o formato de Arranjos de Desenvolvimento da Educação (ADE). Este modelo de gestão em rede, em parceria público/privado, conta com o apoio da União Europeia e com o financiamento do Banco Interamericano de Desenvolvimento (BIRD) e incentivos do Compromisso Todos Pela Educação $^{6}$ e do Projeto Brasil Municípios ${ }^{7}$.

A proposição do ADE origina-se no período de lançamento do Plano de Desenvolvimento de Educação (PDE) em 2007, quando o empresariado paulista tenciona o Ministério da Educação a apoiar um conjunto de medidas para incentivar o fluxo empresarial na gestão educacional, que culminou no movimento Todos Pela Educação (TPE). O movimento conta com uma coordenação nacional, com apoio da Rede Globo dentre outras Emissoras de Rádio e Jornais, Fundação Victor Civita, Fundação Ayrton Senna, Fundação Bradesco, Fundação Itaú, Instituto Votorantim, dentre outras Empresas.

O primeiro Estado a ser escolhido para iniciar o processo de implantação de ADE no país foi a Bahia, em 2009. Tendo como entidades parcerias diversas instituições, entre elas o Instituto Votorantim, foi criado o ADE do Recôncavo Baiano. Este ADE da Bahia foi composto por 12 Municípios: Amargosa, Cabaceiras de Paraguaçu, Cachoeira, Cruz das Almas, Governador Mangabeira, Maragogipe, Muritiba, Rafael Jambeiro, Santo Antônio de Jesus, Santo Estevão, São Félix e São Francisco do Conde. Mas, a iniciativa não logrou êxitos significativos e encontra-se desativado. A experiência foi disseminada depois em Pernambuco, Pará, Tocantins, Sergipe, Paraná, Espírito Santo e São Paulo. Os resultados das pesquisas e consultas em documentos públicos realizados até o presente, tem revelado que o número de ADE no país cresceu muito nos últimos anos. O movimento Todos Pela Educação

\footnotetext{
${ }^{6}$ O Plano de Metas Compromisso Todos pela Educação é um conjunto de medidas para ampliar a qualidade do ensino público brasileiro e representa a conjugação dos esforços da União, Estados, Distrito Federal e Municípios, em regime de colaboração, com a participação das famílias e da comunidade, em proveito da melhoria da qualidade da educação básica (MEC, 2007).

${ }^{7}$ O Projeto Brasil Municípios é uma iniciativa da Secretaria de Gestão do Ministério do Planejamento (SEGES), cujo objetivo é promover o fortalecimento da gestão municipal no país por meio da formação de gestores e técnicos municipais, de consultoria e assistência técnica aos municípios, visando orientá-los na solução de problemas da gestão municipal, incentivando-os no fomento e desenvolvimento de experiências inovadoras de gestão local, por meio do fortalecimento do associativismo intermunicipal.
} 
incentivou e orientou mais de 200 municípios brasileiros a organizarem-se em redes educativas sob o discurso de que essas redes promoveriam a governança local.

Durante o $5^{\circ}$ Fórum Nacional de Educação realizado em Campinas em 2010, Mozart Neves Ramos, presidente-executivo do movimento Todos Pela Educação (TPE), afirmou que o projeto de Arranjos de Desenvolvimento da Educação objetiva desenvolver uma metodologia capaz de apoiar os municípios a alavancar seus indicadores educacionais, visando a melhoria da qualidade da educação no âmbito local, em uma ação conjunta como o MEC e outros parceiros. Segundo ele, o ADE é um modelo de gestão em rede, no qual um grupo de municípios com proximidade geográfica e características sociais e econômicas semelhantes, busca trocar experiências e solucionar problemas educacionais conjuntamente.

O movimento TPE ganhou adesão do Conselho Nacional de Procuradores Gerais do Ministério Público. Em 2010 foi criada uma comissão na Câmara de Educação Básica - CEB do Conselho Nacional de Educação - CNE, através da Portaria n ${ }^{\circ}$ 7/2010 com a finalidade de analisar a proposta dos ADEs como um modelo de fortalecimento do regime de colaboração. Após a aprovação do Parecer CNE o 09/2011, o CNE publicou a Resolução CNE nº 01/ de 2012 que regulamenta a atuação dos ADE nos territórios e afirma em seu art. $1^{\circ}$ que o formato da gestão em ADE pretende contribuir na estruturação e aceleração de um Sistema Nacional de Educação (BRASIL, RES CNE nº 1/1012, art. $1^{\circ}$ ).

O CNE considera que, por meio de um planejamento integrado dos ADEs em âmbito territorial, os municípios podem realizar ações como: planejamento da rede física escolar, cessão mútua de servidores, gestão do transporte escolar, políticas de formação continuada, organização de um sistema de avaliação, captação de recursos para prestação associada de serviços, estruturação de Planos Intermunicipais de Educação visando ao desenvolvimento integrado do território e a redução de disparidades sociais e econômicas locais. Dessa forma os Municípios de menor capacidade técnica podem se valer desses planos na elaboração e execução de suas metas educacionais.

O CNE define o ADE como uma forma de colaboração territorial basicamente horizontal. Nesse sentido, sua implementação deveria priorizar a identificação das instituições e organizações educacionais endógenas que existem e atuam nos espaços territoriais. Porém, observa-se que a formação dos ADE's no Brasil não tem tido este foco democratizante de considerar em sua institucionalização as rugosidades territoriais e assegurar a participação das organizações sociais dos territórios nessa articulação, de forma a promover o desenvolvimento educacional e social do poder local. O que se tem visto é uma série de grandes empresas nacionais e internacionais, da área empresarial, barganhando espaço para atuar na gestão 
compartilhada da educação. O modelo de ADE que vem sendo implantado no país caracterizase como uma gestão em parceria público/privado, através da qual, fundações, institutos, dentre outras entidades do Terceiro Setor, sob a égide do princípio de subsidiariedade, vem passando a ter um papel significativo na gestão da coisa pública, imprimindo ideais neoliberais na gestão da educação.

Importa ressaltar o interesse de deputados em regulamentar os ADEs em parceria público privado, a exemplo da deputada Raquel Teixeira (PSDB-GO) que apresentou no Congresso o PL 7.420/2006 por meio do qual propunha que a União considerasse o ADE como forma de assistência técnica e financeira, demonstrando assim o interesse político de garantir o repasse direto de recursos públicos para tais arranjos. Nessa mesma perspectiva, o deputado Federal Alex Canziani (PTB-PR), apresentou o Projeto de Lei no 2.417. Este foi apensado e os dois estão em tramitação para análise conjunta. Esses deputados que atuam na defesa dos ADE pretendem assegurar na legislação, a possibilidades do aporte de recursos públicos para que empresas possam desenvolver políticas colaborativas em contextos locais. Considerando que tias empresas possuem natureza jurídica privada, cujo propósito de existência é a obtenção de lucro, nota-se aqui um conflito de interesses. O que essas empresas vislumbram na gestão compartilhada da educação com o Estado, não é a garantia de direitos da população, mas a possibilidade de um grande negócio.

O interesse de empresários e políticos na implementação dos ADE's enquanto forma de assistência técnica e financeira, tem gerado debates, demonstrando a necessidade de aprofundar estudos sobre o assunto. Diversas pesquisas de Gilda Araújo (2012; 2013) alertam para o fato de que as formas de colaboração do ADE - baseando-se em conceitos de territorialidade, associativismo intermunicipal voluntário, redes, com parcerias público/privado, com ideais de protagonismo local e visão estratégica, de matriz empresarial - pode representar uma tendência a suprimir a responsabilização compartilhada da União no desenvolvimento da educação básica. O ADE, segundo a autora reforça o ideal de municipalização do ensino fundamental, sem alterar, qualitativamente, a política de financiamento por parte da União para os entes federados.

Importa atentar-se para o fato de setores do empresariado paulista, ligados ao movimento TPE, estarem ocupando lugares estratégicos no governo, como é o caso do CNE e do Congresso para garantirem a aprovação de sua agenda política. Sobre este fato, Gilda Araújo (2012) alerta que estes formatos de ADE's de base empresarial vêm imprimindo a 
lógica dos Arranjos Produtivos Locais numa perspectiva neoliberal, provocando com isso, a despolitização do regime de colaboração.

Em meio a regulações difusas e conflituosas da gestão da educação em um Estado capitalista que possui interesses de mercado, mas também é tencionado a assegurar direitos e garantir a democracia, Dagnino (2004) sinaliza uma crise discursiva resultada de uma 'confluência perversa' entre: de um lado, um projeto neoliberal, com a emergência de um projeto de Estado mínimo que se isenta progressivamente de seu papel de garantidor de direitos, através do encolhimento de suas responsabilidades sociais e sua transferência para a sociedade civil e iniciativa privada; e, de outro, um projeto democratizante, participatório, que surge da resistência dos movimentos sociais para o aprofundamento democrático, que se expressa na criação de espaços públicos de discussões e decisões e na crescente participação da sociedade civil na gestão pública, cujo marco formal é a Constituição de 1988.

Para Dagnino (2004) a perversidade dessa confluência estaria assentada no fato de que, embora os dois projetos apontem e intencionem rumos para direções opostas e até antagônicas, ambos apresentam em seus discursos os ideais de uma sociedade civil ativa e propositiva, com interesses aparentemente comuns de participação, cidadania e democracia. Mas, segundo a autora, de fato não o são. As duas tendências abrigam significados muito distintos, instalando o que a ela chama de crise discursiva, por meio da qual um discurso aparentemente homogêneo, obscurece as diferenças conceituais e reduz antagonismos existentes. Por conta desse obscurecimento, se constroem canais por onde avançam as concepções neoliberais, com projetos de iniciativas e interesses privados em terrenos que seriam de esfera pública. Nesses conflitos semânticos, em que "os deslocamentos de sentido são as armas principais, o terreno da prática política se constitui num terreno minado, onde qualquer passo em falso nos leva ao campo adversário" (DAGNINO, 2004, p. 198).

Considerando a coexistência de dois arranjos em movimento, CP e ADE público/privado, importa aprofundar estudos sobre ambos, de forma a melhor compreender seu projeto político, tanto no campo jurídico, político, teórico quanto no campo empírico, com vista a desvendar seus princípios e suas reais possibilidades de compor, enquanto instância institucionalizada, formas de gestão colaborativa e cooperativa do SNE. O que se pode afirmar, até o presente momento, é que a constituição desses arranjos se encontra ainda confusa e a necessitar de investigações, pois as ausências de análises sobre os discursos e concepções de Estado que embasam estas políticas, não nos permitem a compreensão com a devida parcimônia de distintos projetos políticos, que se encontram, não em disputa, mas em confluência em diferentes territórios do país. Importa investigar se tais arranjos, embora 
situados em campos políticos por vezes antagônicos, possuem interesses comuns, capazes de garantir a qualidade da educação e o direito educacional.

Importa ainda investigar sob que concepções o Estado capitalista atual vem disseminando as propostas de ADE. Tais políticas têm seus fundamentos na concepção de Estado Rede de Castells (2016), uma forma contemporânea de atuação do Estado, por meio da qual o mesmo passa a compartilhar sua autoridade por meio de relações com instituições públicas e privadas, articulando-se por meio de diferentes relações intermodais em âmbito nacional, territorial, local e supranacional. Conforme Castells (2016) o Estado Rede compartilha o exercício de poder com instituições capitalistas adequando-se à globalização, mas, precisa atentar-se para o perigo de perder para estas o poder de coordenação dessas relações.

O incentivo à instituição de ADE no Brasil liderado pelo terceiro setor, representado por grandes empresas, e quase sem nenhuma inclusão efetiva e democrática de organizações sociais do terceiro setor mais endógeno dos diferentes territórios de identidade, poderá incorrer na exclusão dos sujeitos locais nessa rede federativa e no risco da negociação da democracia e do direito à educação pública, gratuita e de qualidade social.

\section{À GUISA DE CONCLUSÕES}

Considerando que os arranjos institucionais para a gestão da educação se constituem em fenômenos políticos recentes, ainda em processo de desenvolvimento, articulados no tempopresente, a análise do objeto em movimento se faz complexa. Portanto, o presente trabalho não propõe trazer conclusões, mas compreender os formatos de gestão compartilhada baseados no associativismo intermunicipal no espaço territorial através dos $\mathrm{CP}$, e, sobretudo dos ADE's no Brasil, a partir do discurso das novas perspectivas da gestão em rede das políticas públicas sociais no Estado contemporâneo.

O formato de Consórcios Públicos na área educacional necessita de estudos, para que se possa explorar suas potencialidades e ampliar sua atuação na área da educação entre as municipalidades para o alcance das metas educacionais. Por outro lado, os formatos de arranjos, sobretudo aqueles com empresas de fins lucrativos em sentido restrito, precisam ser tencionados, debatidos, refletidos para que não incorra em um contra movimento de processos emancipatórios no espaço territorial. 
Convém questionar se tais arranjos poderão assegurar o direito à educação com equidade nas diferentes regiões do país e, por fim, indagar: ao propor a instituição de arranjos institucionais para promover a colaboração e a cooperação federativas sem a existência de um SNE, estará o governo brasileiro estabelecendo políticas capazes de assegurar o direito à educação com equidade, em redes colaborativas mais abrangentes, por meio da proposta de um Estado Rede que se adequa ao espaço-tempo contemporâneo? Ou estará o poder político, unido ao poder jurídico, apenas conformando o direito educacional aos interesses dos novos fluxos do capital?

Sabendo que toda política pública resguarda em si uma determinada concepção de sociedade e de Estado em certo espaço-tempo, para melhor compreender a gestão de políticas no espaço territorial por meio dos arranjos institucionais faz-se necessário compreender o Estado brasileiro capitalista em movimento na contemporaneidade. É certo que o espaçotempo atual demanda uma nova configuração do poder do Estado, com a inclusão de novos sujeitos para a inovação na gestão, mas, convém atentar-se para a identidade e os reais interesses desses sujeitos. Compreendendo a lógica do contrato social do Estado capitalista atual, seu curso e discurso, pode-se conhecer o objeto em estudo em sua dimensão política mais ampla. Mas, este é um assunto para outro debate.

\section{REFERENCIAS}

ABICAIL, Carlos Augusto. O Plano Nacional de Educação e o regime de colaboração. Revista Retratos da Escola. v. 8, n. 15, p. 249-263, 2014.

ABRUCIO, Fernando Luiz; CUNHA, Célio da. O Manifesto dos Pioneiros e o federalismo brasileiro: percalços e avanços rumo a um Sistema Nacional de Educação. In: Sistema Nacional de Educação: diversos olhares 80 anos após o Manifesto. Brasília: Ministério da Educação, p. 40-57, 2014.

, Fernando Luiz; SEGATTO, Catarina Ianni. A cooperação em uma federação heterogênea: o regime de colaboração na educação em seis estados brasileiros. Fundação Getúlio Vargas, São Paulo. Revista Brasileira de Educação. v. 21 n. 65 abr.-jun. 2016.

ARAUJO, Gilda Cardoso. Federalismo Cooperativo e Arranjos de Desenvolvimento da Educação: um atalho silencioso do empresariado para a definição e regulamentação do regime de colaboração. In: RBPAE, v. 28, n 2, p. 515-531maio/ago, 2012.

Gilda Cardoso. Federalismo e políticas educacionais no Brasil: equalização e atuação do empresariado. Educ. Soc., Campinas, v. 34, n. 124, p. 787-802, jul.-set. 2013. 
BAHIA. Secretaria de Planejamento. Consórcio Público: Orientações Gerais Para Implantação. Cartilha em PDF. Disponível pra Download no site www.seplan.gov.ba.br. Acesso em 10 setembro de 2017.

BRASIL, Constituição da República Federativa do Brasil (1988). Promulgada em 05 de outubro de 1988. Disponível em: <www.planalto.gov.br/ccivil_03/constituicao. Acesso em: Acesso em 20/02/2018.

, Emenda Constitucional no 59. Brasília, DF, 2009.

Decreto 6.017/07. Regulamenta a Lei no 11.107, de 6 de abril de 2005, que dispõe sobre normas gerais de contratação de consórcios públicos., Brasília, DF: 2007.

Decreto 6.094/07. Dispõe sobre o Compromisso Todos Pela Educação: Brasília, DF:MEC, 2007.

Lei 11.107 de 06 de abril de 2005. Dispõe sobre normas gerais de contratação de consórcios públicos e dá outras providências. Disponível em www.senado.gov.br. Acesso em: 20/02/2018.

Lei 13.005 de 25 de junho de 2014. Aprova o Plano Nacional de Educação, Brasília, DF: MEC, 2014.

Manual do Plano de Desenvolvimento da Educação: Razões, Princípios e Programas. Brasília, 2007.

Parecer $\mathbf{n}^{\circ}$ 9, de 30 de agosto de 2011. Análise de proposta de fortalecimento e implementação do regime de colaboração mediante arranjos de desenvolvimento da educação. Brasília, DF: MEC/ CNE, 2011.

, Resolução n 1 , de 23 de janeiro de 2012. Dispõe sobre a implementação do regime de colaboração mediante Arranjo de Desenvolvimento da Educação (ADE) como instrumento de gestão pública para a melhoria da qualidade social da educação. DF: MEC/CNE, 2012

CASTELLS, Manuel. Sociedade em Rede. Tradução Roneide Venancio Majer. $17^{\text {a }}$ Edição. São Paulo: Paz e Terra, 2016

CEZAR, Paulo Sérgio Mendes César - Consórcios Públicos e o principio da eficiência na administração pública. Monografia. Faculdade de Direito - UFMG. Belo Horizonte, 2008.

CURY, Carlos Roberto Jamil. A Educação Básica o Brasil. Educação e Sociedade Campinas, v 23, n 80, setembro de 2002, 168-200. Disponível em: http://www.cedes.unicamp.br.

Carlos Roberto Jamil. A questão federativa e a educação escolar. In: Educação e federalismo no Brasil: combater as desigualdades, garantir a diversidade. Brasília: UNESCO, 2010 .

DAGNINO, Evelina. ¿Sociedade civil, participação e cidadania: de que estamos falando? Em Daniel Mato (coord.), Políticas de ciudadanía y sociedad civil entiempos de globalización, Caracas: FACES, Universidad Central de Venezuela, pp. 95-110. 2004. 
GRAÇA SOUTO, A. C. Consórcios Intermunicipais e Federalismo Cooperativo. Parecer jurídico. Brasília, 2007. Disponível em: <http://www.alcoforadoadvogados.

IBDM. Instituto Brasileiro de Desenvolvimento Municipal. Diário Oficial Eletrônico dos Municípios. Disponível em: http://www.ibdm.org.br/ba. Acesso em: 22 de jun. 2018.

PRATES, Ângelo Marcos Queiróz. Os consórcios públicos municipais no Brasil e a experiência europeia: alguns apontamentos Para o desenvolvimento local. III Congresso Consad de Gestão Pública. Brasília, DF, 2010.

RIBEIRO, Hilton Manoel Dias. FERNANDES, E.; RIBEIRO, Ivo. C. D. Análise de Capital Social na Zona Rural dos Municípios pertencentes ao Consórcio de Desenvolvimento do Alto Paraopeba - CODAP - MG. Anais do $49^{\circ}$ Congresso da SOBER - Belo Horizonte, 2011.

RIBEIRO, Wladimir António. Cooperação Federativa e a Lei dos Consórcios Públicos. CNM Publicações. Brasília, 2006. 